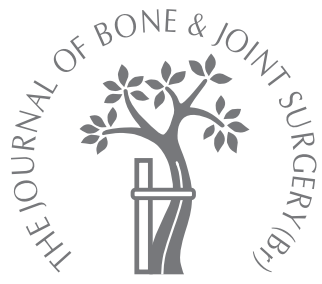

J. S. Church,
W. H. Breidahl,
G. C. Janes
From Perth
Orthopaedic and
Sports Medicine
Centre, Perth,
Western Australia

J. S. Church, BSc, FRCS(Tr \& Orth), Orthopaedic Fellow

17 Inman Road, London SW18 3BB, UK.

W. H. Breidahl, MRCP, FRANZCR, Radiologist Perth Radiology Clinic, 127 Hamersley Road, Subiaco 6008, Western Australia, Australia.

m G. C. Janes, FRACS(Orth), Orthopaedic Surgeon Perth Orthopaedic \& Sports Medicine Centre, 31 Outram Street, West Perth 6005,

Western Australia, Australia.

Correspondence should be sent to Mr J. S. Church; e-mail: j.s.church@btinternet.com

(c)2006 British Editorial Society of Bone and Joint Surgery doi:10.1302/0301-620X.88B5. $17579 \$ 2.00$

$J$ Bone Joint Surg [Br] 2006;88-B:673-5.

Received 22 December 2005; Accepted 18 January 2006

CASE REPORT

\title{
Recurrent synovial chondromatosis of the knee after radical synovectomy and arthrodesis
}

\begin{abstract}
We describe a case of highly refractory synovial chondromatosis, which recurred despite four arthroscopic synovectomies, a chemical synovectomy, two open synovectomies and an arthrodesis. A review of the literature revealed one similar case. Both presented with marked joint stiffness suggesting a poor prognosis. Although arthrodesis may relieve short-term symptoms it does not prevent further recurrence of disease.
\end{abstract}

\section{Case report}

In January 1996, a 24-year-old female teacher and national-standard hockey player was seen with a three-month history of progressive loss of movement and locking of the right knee. On examination, she had a diffusely swollen joint with a fixed-flexion deformity of $45^{\circ}$ and flexion to $90^{\circ}$. She underwent an arthroscopy at her local hospital during which multiple chondromata were removed. Histology of these chondromata revealed variably sized nodules of hyaline cartilage, some which which were undergoing dystrophic calcification. Synovial chondromatosis was diagnosed. Following arthroscopy and two subsequent injections of cortisone, the patient's range of movement improved and she was able to return to playing hockey. However, within three months, her symptoms returned with associated pain and swelling. This persisted despite an attempted chemical synovectomy with a course of yttrium injections and two further arthroscopic debridements. By November 1997, she had a fixedflexion deformity of $40^{\circ}$ with flexion to only $50^{\circ}$. An MRI scan revealed extensive synovial fibrosis with a loose body, $4 \mathrm{~cm} \mathrm{x} 4 \mathrm{~cm}$, in the posterior compartment of the knee (Fig. 1).

She was referred to the regional tertiary centre, where it was decided to perform an open synovectomy and removal of loose bodies. Histology, following the procedure, confirmed the diagnosis of recurrent synovial chondromatosis. Following this, however, her pain and reduced movement persisted and, in April 1998, she underwent a radical open synovectomy. This included the removal of both the menisci and cruciates, which improved her pain with a range of movement from $10^{\circ}$ to

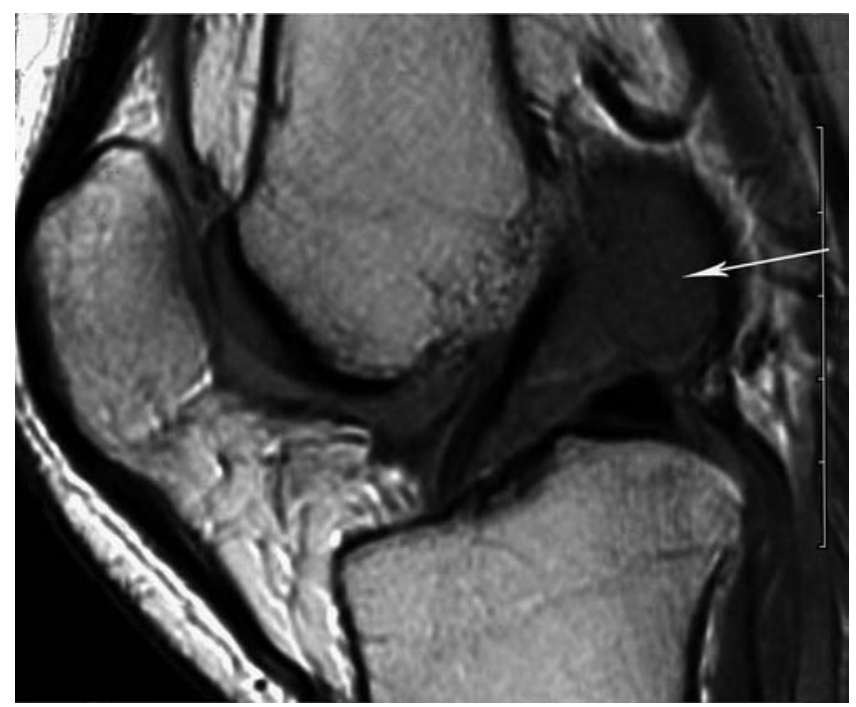

Fig. 1

Sagittal proton density image through the intercondylar region of the right knee. A large, low-signal-intensity mass lies posterior to the anterior cruciate ligament (arrow). 


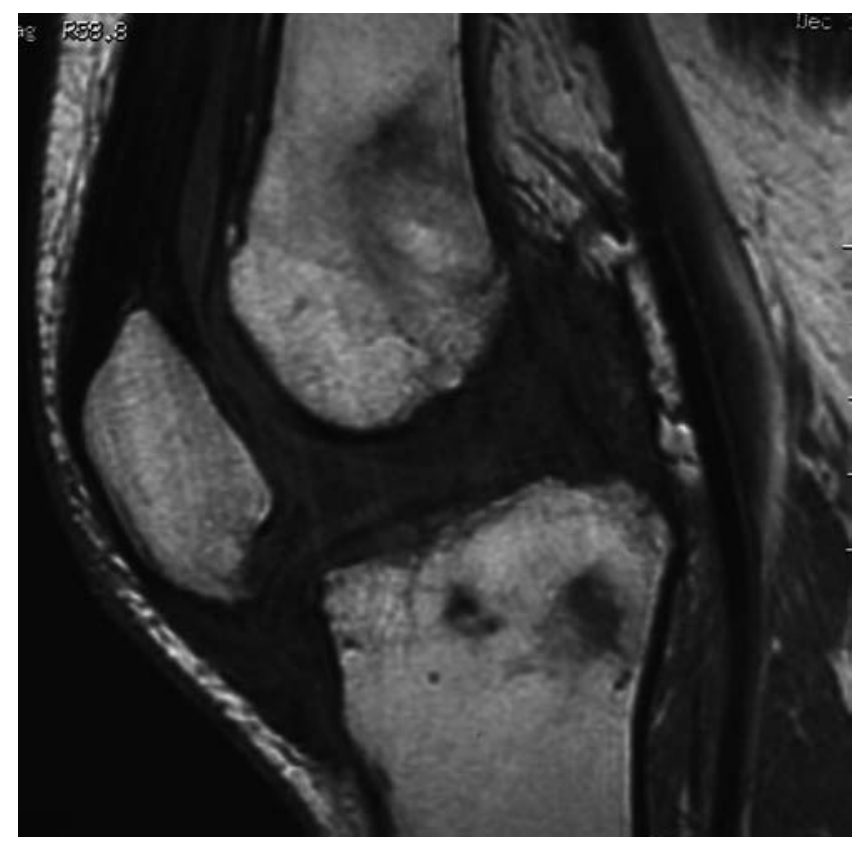

Fig. 2

Sagittal proton density image through the intercondylar region of the right knee. There is extensive fibrosis in the intercondylar region and the fat pad. Patella baja has developed.

$100^{\circ}$ of flexion. Unfortunately, the improvement was brief. Over the following year she underwent a further arthroscopic debridement, daily continuous passive movement and correction of the fixed-flexion deformity with a circular frame. Despite this, she continued to experience constant pain in the knee and a limited range of movement from $0^{\circ}$ to $10^{\circ}$ of flexion. An MRI scan showed significant intraarticular fibrosis but no evidence of recurrence (Fig. 2).

In April 2001, arthrodesis of the knee was successfully undertaken using a circular frame. The pain resolved and she was able to return to an active lifestyle, which included participating in triathlons. In April 2005, however, she presented with a nine-month history of progressive night pain, which had not responded to anti-inflammatory medication. A further MRI scan revealed a solid fusion, but with multiple foci of nodular synovial proliferation in the medial and lateral gutters, intercondylar notch and along the popliteus tendon, consistent with a diagnosis of recurrent synovial chondromatosis (Fig. 3).

\section{Discussion}

Synovial chondromatosis is a rare, benign condition characterised by cartilaginous metaplasia of the intimal layer of the synovial membrane of joints, tendons and bursae. Jaffe described the condition in $1958,{ }^{1}$ and the knee is the most commonly affected joint. ${ }^{1-4}$ The early literature focused on the primary management of this condition. Murphy et $\mathrm{al}^{2}$ described 32 patients treated at the Mayo clinic with open removal of loose bodies and affected synovium. There was

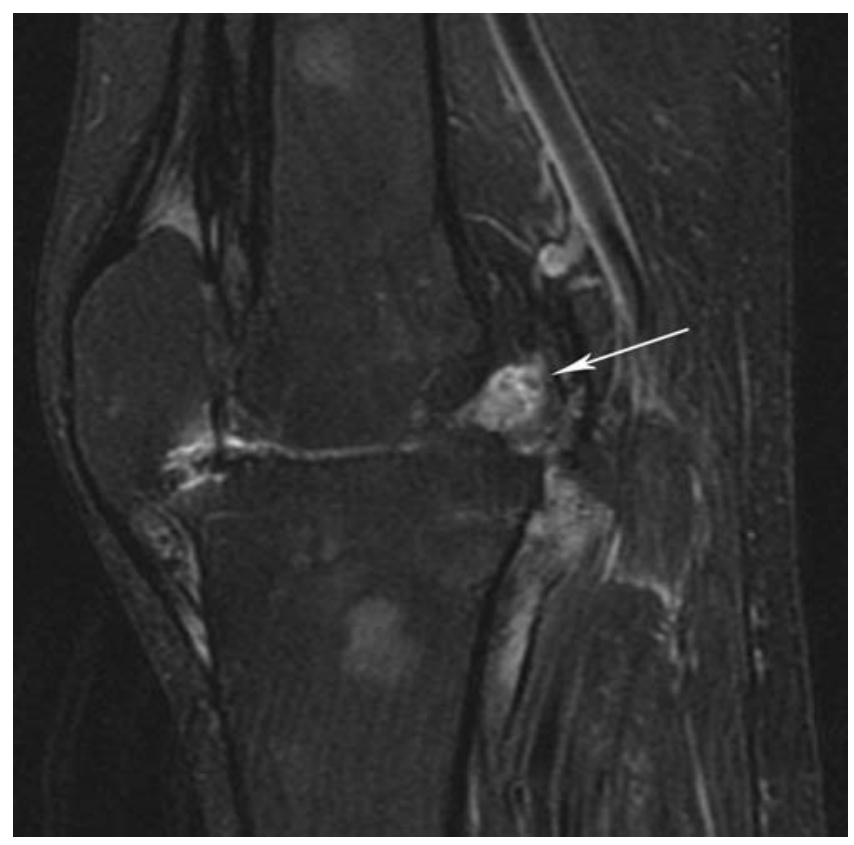

Fig. 3a

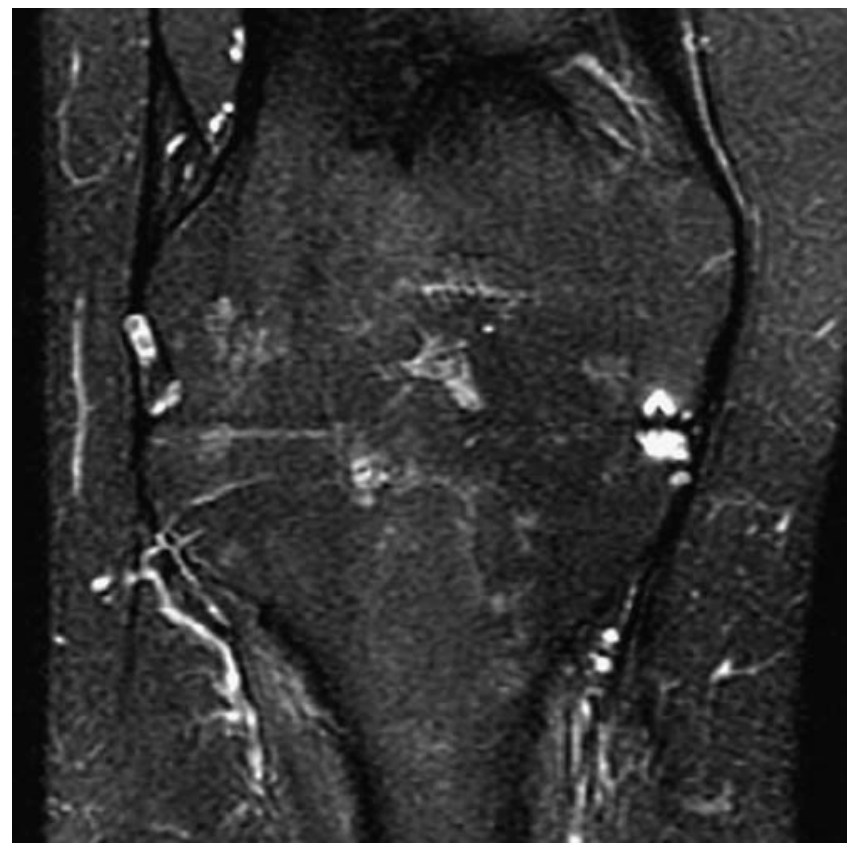

Fig. $3 b$

MRI scans performed in April 2005, demonstrating, a) sagittal T2weighted fat-suppressed image after arthrodesis. The recurrent synovial chondromatosis appears as an area of relatively high signal intensity posteriorly (arrow) and, b) coronal T2-weighted fat-suppressed image demonstrating no residual joint space.

only one recurrence. Jeffreys ${ }^{3}$ reviewed 17 cases treated surgically, with no recurrences. His paper concluded that removal of the loose bodies alone was preferable to synovectomy, because there was less post-operative stiffness 
and complete synovectomy was 'impracticable'. In 1989, Coolican and Dandy ${ }^{1}$ reported that arthroscopic removal of loose bodies and the affected synovium achieved better results than open procedures, and in the same year Dorfmann et $\mathrm{al}^{5}$ concluded that arthroscopic removal of the loose bodies alone gave satisfactory results. This was disputed by Ogilvie-Harris and Saleh ${ }^{6}$ in 1994, who found a significant difference between the rates of recurrence after arthroscopic removal of the loose bodies and arthroscopic synovectomy. All recurrences were subsequently treated successfully with an arthroscopic synovectomy.

One can, therefore, conclude that recurrence of synovial chondromatosis is rare, particularly after synovectomy. The majority of the reported recurrences have responded well to a repeat procedure. We could only find one report of a highly refractory synovial chondromatosis similar to our case. This was the one failure reported by Coolican and Dandy ${ }^{1}$ in which the patient presented with a range of movement from $45^{\circ}$ to $90^{\circ}$ of flexion. After three arthroscopic synovectomies and removal of loose bodies, an arthrotomy and an open synovectomy, the patient still complained of severe pain and stiffness. A manipulation under anaesthetic was performed which resulted in a fracture of the femur. When this had united, the patient was left with $20^{\circ}$ of movement in the knee and an arthrodesis was offered. No further information was available as to the eventual outcome of this patient.

The primary complaint in both our case and that of Coolican and Dandy ${ }^{1}$ was of significant stiffness, both having a range of movement from $45^{\circ}$ to $90^{\circ}$ of flexion at presentation. Synovial chondromatosis most commonly presents with pain and swelling in the affected joint. ${ }^{1,3}$ Stiffness was reported as a secondary symptom in only two of eight patients of Jeffreys, ${ }^{3}$ all of whom complained primarily of pain and swelling, and loss of extension was noted in five of 18 knees by Coolican and Dandy. ${ }^{1}$ In their case of recurrence and in ours, the stiffness was severe and was the primary complaint, suggesting a poor prognosis. The stiffness in our case could be caused by a thickened, metaplastic synovium coupled with the presence of multiple loose bodies within the knee.

Arthrodesis has previously been reported to be a successful salvage procedure for recurrent synovial chondromatosis. Harvey and Negrine ${ }^{7}$ carried out an arthrodesis of the distal interphalangeal joint of the middle finger and reported no recurrence after three years. Hocking and Negrine ${ }^{4}$ subsequently described the successful outcomes of two arthrodeses performed for synovial chondromatosis of the subtalar joint at five years. To the best of our knowledge, ours is the first outcome report of arthrodesis for refractory synovial chondromatosis of the knee and is the first reported case of recurrence in any joint after arthrodesis. Although the arthrodesis initially provided significant pain relief and functional improvement, it did not prevent recurrence of the synovial chondromatosis.

No benefits in any form have been received or will be received from a commercial party related directly or indirectly to the subject of this article.

\section{References}

1. Coolican MR, Dandy DJ. Arthroscopic management of synovial chondromatosis of the knee: findings and results in 18 cases. J Bone Joint Surg [Br] 1989;71-B:498-500.

2. Murphy FP, Dahlin DC, Sullivan CR. Articular synovial chondromatosis. J Bone Joint Surg [Am] 1962;44-A:77-86.

3. Jeffreys TE. Synovial chondromatosis. J Bone Joint Surg [Br] 1967;49-B:530-4.

4. Hocking R, Negrine J. Primary synovial chondromatosis of the subtalar joint affecting two brothers. Foot Ankle Int 2003;24:865-7.

5. Dorfmann H, De Bie B, Bonvarlet JP, Boyer T. Arthroscopic treatment of synovial chondromatosis of the knee. Arthoscopy 1989;5:48-51.

6. Ogilvie-Harris DJ, Saleh K. Generalized synovial chondromatosis of the knee: a comparison of removal of the loose bodies alone with arthroscopic synovectomy. Arthroscopy 1994;10:166-70.

7. Harvey FJ, Negrine J. Synovial chondromatosis in the distal interphalangeal joint. J Hand Surg [Am] 1990;15:102-5. 